\title{
AN EVALUATION OF DISCREPANCY IN CAPACITY AND CONTOUR OF THE NEUROGENIC BLADDER AS SHOWN ON CYSTOGRAPHY AND PYELOGRAPHY
}

\author{
By A. T. Scher, M.B., Ch.B., D.M.R.D. \\ Department of Radiology and Spinal Cord Injuries Centre, \\ Conradie Hospital, Cape Town, South Africa
}

\section{Introduction}

ASSESSMENT of the bladder capacity and contour in patients who have suffered injury to the spinal cord, forms an important part of the evaluation of the patient's urinary status.

Interference with the nerve supply of the bladder as a result of spinal cord injury or disease, results in a bladder of impaired function, i.e. a neurogenic bladder. Depending on the level of the spinal cord injury and degree of damage to the spinal cord, the neurogenic bladder may fall into one of two groups: the Upper Motor Neuron or Lower Motor Neuron type. The capacity of the bladder differs markedly between these two groups.

During an investigation into diagnostic and technical difficulties associated with micturating cystourethography in patients with neurogenic bladders, Scher (I977), a marked difference in the capacity and contour of the contrast filled bladder on cystography as compared to intravenous pyelography was noted. This discrepancy may lead to erroneous diagnosis of the status and condition of the neurogenic bladder, and further investigation into these differences in radiological appearances has therefore been undertaken.

\section{Material and Methods}

The capacity of the contrast filled bladder as demonstrated by intravenous pyelography and subsequently by cystography, was compared in 50 patients with post-traumatic tetraplegia or paraplegia. The cases were unselected and sequentially studied as the examinations became available. The intravenous pyelograms were performed from 48 to 72 hours before the micturating cystourethrogram. These examinations are performed annually on all patients treated at the Spinal Cord Injuries Centre. There were 42 male and eight female patients in the series. The duration of paralysis varied from I to Io years post-injury. In 38 of these patients complete motor and sensory paralysis below the level of spinal cord injury was present. The remaining 12 patients had incomplete paralysis below the level of injury.

Bladder capacity as demonstrated on intravenous pyelography was assessed on a full-length radiograph obtained 20 minutes after the administration of $90 \mathrm{ml}$ Sodium Iothalomate (Conray 325) by drip infusion. On cystography assessment was made after maximal filling of the bladder by gravity, using a Foley's catheter and a glass funnel. The funnel is held at a maximum height of $30 \mathrm{~cm}$ above the patient's symphisis pubis during the examination. The contrast medium used for cystography was Sodium Iodide 13.5 per cent, warmed to body temperature. 


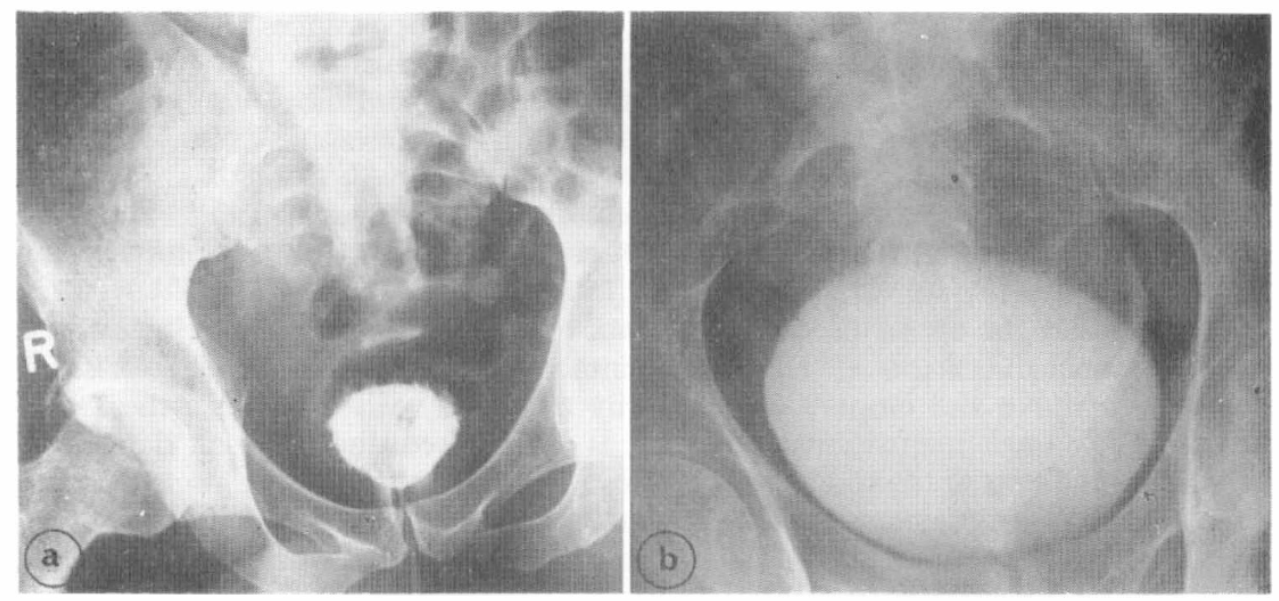

FIG. I (a)

Cystogram of paraplegic patient demonstrating apparently marked trabeculation of the bladder wall and small capacity bladder.

FIG. I $(b)$

Intravenous pyelogram of same patient demonstrating normal bladder contour and good filling of the bladder.

Assessment of bladder capacity on the radiographs was made by means of a Planimeter. This is an instrument which accurately measures the surface of plane areas having either straight or curvi-linear borders. Good correlation between the actual volume of contrast in the bladder and the volume as measured by the planimeter has previously been shown by Griffiths and Castro. The planimeter was calibrated on radiographs obtained after instilling measured quantities of contrast into the bladder of a non-paraplegic patient with normal bladder innervation.

\section{Results}

In 16 ( 32 per cent) of the 50 patients, a significant difference in bladder volume was present. A 'significant difference' for the purpose of this investigation was defined as a difference of $50 \mathrm{ml}$ or more in bladder volume as judged on the two examinations. In these patients the average bladder capacity assessed on the pyelogram was $250 \mathrm{ml}$, and the average capacity assessed on cystography was $55 \mathrm{ml}$. A mean difference of $\mathrm{I} 95 \mathrm{ml}$. (Figs $\mathrm{I}(a)$ and $\mathrm{I}(b)$ ) illustrates the difference in bladder capacity.

In all I6 patients the bladder wall appeared trabeculated on cystography, but in the better filled bladder present on the pyelogram, the bladder contour was normal in appearance. Thirteen of the 16 patients had sustained injury to the cervical or thoracic spinal cord ( $\mathrm{TI}_{\mathrm{I}} \mathrm{T}$ 9), while the remaining three patients had sustained trauma to the dorso-lumbar spine (Tro-L2). In I 2 patients complete paralysis was present. In the other four patients paralysis was incomplete.

\section{Discussion}

The capacity of the bladder and the degree of trabeculation of the bladder wall as demonstrated on cystography are used in our evaluation of the bladder 
after spinal cord injury, Key (1972). The cystographic appearances are also used by other spinal cord injury units, Burke, Guttman. In an evaluation of cystourethography in patients with spinal cord injuries, Pritzel and Bors considered any bladder in which both the horizontal and vertical cystographic axes were $7 \mathrm{~cm}$ or less as a 'contracted bladder'.

Depending on the type of neurological deficit, neurogenic bladders may be considered as falling into one of three groups. These are, Upper Motor Neuron (U.M.N.), Lower Motor Neuron (L.M.N.), or mixed (U.M.N.-L.M.N.). In the UMN bladder the spinal cord lesion is above the level of the conus medullaris and the spinal micturitional reflex arc is intact. The bladder is usually of small capacity, irritable and empties involuntarily as it fills with urine. In the LMN bladder the spinal micturitional reflex arc is interrupted due to direct damage to the sacral segments of the spinal cord. These bladders are usually of large capacity, flaccid and will only empty by overflow incontinence.

If cystography alone was used in this series for assessment of bladder type, an erroneous impression of a small capacity bladder, with a trabeculated wall of the UMN group, would have been recorded in 32 per cent of the patients examined. In practice other diagnostic criteria (cystometry, degree of external sphincter resistance, the bulbocavernosus reflex) are used in addition to cystography in order to arrive at a true assessment of bladder type.

If the criteria as suggested above by Pritzel and Bors had been used, 32 per cent of the patients would have been considered as having contracted bladders on cystography, but having normal bladders on intravenous pyelography.

\section{Causes of Apparent Discrepancy of Bladder Capacity on Cystography}

\section{Retrograde introduction of contrast medium into the bladder}

Retrograde introduction of contrast medium may precipitate reflex contractions of the neurogenic bladder. These reflex contractions will occur with the introduction of any type of fluid into the neurogenic bladder. They occur more commonly in the small capacity, irritable UMN bladder.

\section{Irritative effects of contrast medium}

McAlister et al. noted oedema and haemorrhage of the bladder wall occurring shortly after cystography. Under experimental conditions there was no difference in the inflammatory response evoked by different contrast agents. The degree of inflammatory response, however, was related to the concentration and volume of contrast. Dilution of the contrast medium and reduction in the volume used, was shown to reduce the degree of inflammatory response.

The potential for irritation of the mucosal surface of the neurogenic bladder is far higher in cystography, where undiluted contrast medium comes into direct contact with the bladder wall, than in intravenous pyelography, where the contrast has been considerably diluted by the time it enters the bladder.

\section{Introduction of catheter}

In the majority of our patients with spinal cord injury, an indwelling catheter is not used after the acute phase of injury. In order to perform the cystogram it is therefore necessary to catheterise the patient to allow for the introduction of contrast medium. The presence of the recently introduced catheter may also have the effect of inducing reflex contractions of the neurogenic bladder. 


\section{Temperature of contrast medium used for cystography}

Introduction of fluid which has been cooled to just above freezing point, will induce reflex contraction of the detrusor muscle if the spinal micturition reflex arc is intact. This forms the basis of the ice water test which is used for assessment of the autonomic nerve supply of the detrusor muscle in patients with neurogenic bladders. In an attempt to minimise reflex contractions we routinely warm the contrast medium used for cystography to body temperature, therefore the temperature of the contrast it not considered to have influenced our observations in this investigation.

\section{Conclusion}

A significant difference in bladder capacity and contour as demonstrated on cystography and intravenous pyelography was found in 16 ( 32 per cent) of the 50 patients with neurogenic bladders. In these 16 patients the capacity and contour of the bladder were normal in appearance on intravenous pyelography, whereas on cystography the bladder was of small capacity and showed trabeculation of its wall.

These differences in appearances are probably due to a combination of factors which induce reflex contraction of the neurogenic bladder. These factors are, retrograde introduction of contrast medium, irritation of the bladder mucosa by the contrast and irritation of the bladder by the urethral catheter.

If cystography is used in conjunction with intravenous pyelography and cystometry, the discrepancy in radiological appearances is unlikely to lead to erroneous diagnosis. If the cystographic appearances are considered in isolation, however, care must be taken to ensure that the patient with a neurogenic bladder is not erroneously diagnosed as having a small capacity bladder with a trabeculated wall.

\section{SUMMARY}

A significant difference in the filling of the bladder with contrast medium on intravenous pyelography as compared to cystography has been noted in patients with spinal cord injury. Bladder capacity and contour of the bladder wall have been assessed in 50 patients with impaired bladder innervation consequent upon spinal cord injury. In 32 per cent of the patients the bladder capacity was significantly greater when measured on pyelography than that found in cystography. The causes for this discrepancy in bladder filling on the two examinations are discussed. The possibility of erroneous assessment of the capacity and contour of the neurogenic bladder on cystography is pointed out.

\section{RÉSUMÉ}

On note une différence importante dans le remplissage de la vessie avec radio contraste en pyélographie intraveneuse comparée à la cystographie chez les malades accidentes à la moelle épinière. La capacité de la vessie et le contour de ses paroies ont été étudiées chez 50 malades qui avaient des troubles de fonctionnement à cause d'un accident à la moelle épinière. Chez $32 \%$ des malades la capacité de la vessie était indubitablement plus grande quand mesurée au pyélographie que quand trouvée au cystographie. Les causes de cette divergence dans le remplissage de la vessie lors des deux examinations est discutes. La possibilité de jugement erroné de la capacité et du contour de la vessie neurogénique par cystographie est soulignée.

$$
\text { I } 7 / 3-G
$$




\section{ZuSAMMENFASSUNG}

Bei Untersuchungen paraplegischer Patienten wurde ein entscheidender Unterschied bei der Blasenfüllung mit Kontrast Medium bei intravenöser Pyelography fastgestellt im Gegensatz zur Cystography.

Fünfzig paraplegische Patienten mit gestörter Blaseninnervation wurden auf Blasenkapazität und Form der Blasenwand untersucht. $32 \%$ der Patienten zeigten eine bedeutend grössere Blasenkapazität bei der Pyelography als bei der Cystography.

Die Ursachen der Unterschiede bei Blasenfüllung in diesen beiden Untersuchungsmethoden werden besprochen. Die Möglichkeit einer fehlerhaften Untersuchung der Kapazität und Form einer neurogenen Blase bei Cystography wird betont.

\section{REFERENCES}

SCHER, A. T. (1977). Problems in the radiological interpretation of the X-ray appearance of the bladder wall and bladder neck obtained on micturating cystourethography in patients with neurogenic bladders. Int. F. Paraplegia, 15, I5-20.

Griffiths, H. J. L. \& CASTRO, J. (1970). An evaluation of the importance of residual urine. $B r$. F. Radiol., 43, 409-4I3.

KEY, A. G. (I972). The bladder in spinal cord injuries. S. Afr. Med. F., 46, 362-364.

Burke, D. C. \& Murray, D. D. (1973). Handbook of Spinal Cord Medicine, p. 31. Victoria, Australia, Spinal Injuries Unit, Austin Hospital.

Guttman, L. (1973). Spinal Cord Injuries, pp. 327-342. Blackwell Scientific Publications, Oxford.

PRITZEL, J. D. \& BoRs, E. (1966). Is cystourethography of neuro-urologic diagnostic value in patients with spinal cord injury? F. of Urol., 96, 320-327.

MCAlister, W. H., ShackelfoRd, G. D. \& Kissane, J. (I972). The histologic effects of $30 \%$ Cystokon, Hypaque $25 \%$ and Renografin-30 in the bladder. Radiology, I04, 563-565. 